\title{
$\$$ Research Square

\section{YKL-40 Enhanced the Permeability of HDMECs with Histamine Through Activating Akt and p38 Pathways}

\section{Peimei Zhou}

Chengdu Second People's Hospital

\section{Lixin Fu}

Chengdu Second People's Hospital

\section{Tao Chen}

Chengdu Second People's Hospital

\section{Lin Wang ( $\nabla$ lkzwl@126.com )}

Sichuan University West China Hospital https://orcid.org/0000-0001-8704-1136

\section{Yonghong Lu}

Chengdu Second People's Hospital

\section{Wenju Wang}

Chengdu Second People's Hospital

\section{Shihua Zeng}

Chengdu Second People's Hospital

\section{Lin Li}

Chengdu Second People's Hospital

\section{Li Han}

Chengdu Second People's Hospital

\section{Research}

Keywords: YKL-40, CSU, HDMECs, permeability, VE-cadherin

Posted Date: July 27th, 2021

DOI: https://doi.org/10.21203/rs.3.rs-674027/v1

License: (c) (1) This work is licensed under a Creative Commons Attribution 4.0 International License. Read Full License 


\section{Abstract}

Background, YKL-40 is currently considered as an important marker of endothelial dysfunction. Chronic spontaneous urticaria (CSU) is a common vascular skin disease. The increased vascular permeability play an important role in the occurrence and pathogenesis of CSU.

Objective, the aim of this study is to explore the role of YKL-40 on the permeability of HDMECs.

Methods, in this study, the mRNA level of YKL-40 in human mast cell line (HMC-1) were detected by RTPCR. The effects of YKL-40 on vascular permeability, VE-cadherin release, VE-cadherin disruption in human dermal microvascular endothelial cells (HDMECs) were investigated by transwell, ELISA or immunofluorescence. The phosphorylation of VE-cadherin, p38 and Akt, in histamine plus YKL-40 treated HDMECs were detected by Western Blot.

Results, we found that YKL-40 significantly promoted the permeability changes and leaded to the released, disruption of VE-cadherin in HDMECs induced by histamine. Furthermore, YKL-40 also enhanced the Akt and p38 pathways.

Conclusion, we suggest that YKL-40 may serve as pro-permeability cytokines, and play a role in the pathogenesis of CSU. This study will help to further elucidate the pathogenesis of CSU and provide a new target for the development of anti-histamine resistance drugs for CSU.

\section{Introduction}

Chronic spontaneous urticaria (CSU), a common vascular skin disease with high incidence and recurrent attacks, is one of the skin diseases that seriously affect the quality of patients' life(1). Some CSU patients have resistance to treatment. Although the pathogenesis of CSU is complex and not yet fully clear, lots of studies had demonstrated that histamine is the major mediator responsible for CSU. Histamine and other vasoactive substances, released by mast cell degranulation, can ultimately lead to increased vascular permeability, which is considered to be the central link in the pathogenesis of CSU. Bossi et al had reported that the supernatant of human mast cell line (HMC-1), which treated with serum from CSU patients, could increase the permeability of human dermal microvascular endothelial cells (HDMECs)(2).

The stability of vascular permeability depends on the normal function of vascular endothelial barrier. As an important intercellular adhesion molecule, vascular endothelial cadherin (VE-cadherin) plays an important role in the changes of vascular permeability induced by various vasoactive substances (including histamine)(3). The function of endothelial barrier depends on the correct location and function of VE-cadherin. VE-cadherin at the endothelial junction stabilizes the function of endothelial barrier under the action of integrin $\beta 1$ of endothelial cells(4). During vascular injury, VE-cadherin of endothelial cells can be degraded, part of which enters the cytoplasm through endocytosis, and part of which will dissociate into the blood and form soluble VE-cadherin through hydrolysis. 
YKL-40, also described with human cartilage glycoprotein-39 and chitinase-3-like-1, can be secreted and expressed by a series of inflammatory-related cells, including tumor cells, vascular smooth muscle cells, mature neutrophils, articular synovial cells, chondrocytes, hepatic stellate cells, colon epithelial cells, airway epithelial cells and tubular epithelial cells. YKL-40 plays an important role in cell proliferation, microangiogenesis, acute or chronic inflammation. Clinical studies showed that YKL-40 is closely related to many diseases, such as tumors(5), rheumatoid arthritis(6), coronary artery disease(7), pneumonia(8), liver fibrosis(9), chronic pancreatitis(10) and other diseases. The serum level of YKL-40 was increased in many allergic diseases, such as atopic dermatitis(11), asthma(12), and was positively related to the severity of these disease. The expression of YKL-40 in peripheral blood of patients with psoriasis(13) and diabetes(10) were also significantly increased. Therefore, $\mathrm{YKL}-40$ is currently considered to be an important marker of endothelial dysfunction. Our previous study examined the serum levels of YKL-40 in patients with CSU and healthy controls. We found that the serum YKL-40 levels were significantly increased in patients with CSU compared with healthy controls, which indicated that YKL-40 may play an important role in the pathogenesis of CSU(14).

To explore the role of YKL-40 in pathogenic mechanism of CSU, this study investigated the effects of YKL-40 on histamine-stimulated HDMECs in this study.

\section{Materials And Methods}

\section{Cell Culture}

HMC-1 cells were cultured in IMDM with $100 \mathrm{U} / \mathrm{ml}$ of penicillin and streptomycin, and $10 \%$ fetal bovine serum (FBS) at $37 \mathrm{C}$ in $5 \% \mathrm{CO}_{2}$. The cells were stimulated with $50 \mathrm{nM}$ of phorbol 12-myristate 13-acetate (PMA) plus $1 \mu \mathrm{M}$ of $\mathrm{A} 23187$ (calcium ionophore) and incubated at $37^{\circ} \mathrm{C}$ for $8 \mathrm{~h}$.

The HDMECs were cultured in DMEM medium supplemented with $10 \% \mathrm{PBS}, 100 \mathrm{U} / \mathrm{mL}$ of penicillin, and $100 \mathrm{U} / \mathrm{mL}$ of streptomycin. In this study, HDMECs were seeded in plates at $1 \times 10^{5} \mathrm{cell} / \mathrm{cm}^{2}$. After a 48hour incubation, HDMECs were treated with recombinant human YKL-40 (10-500 ng/ml) or histamine plus YKL-40 (10-500 ng/ml) for different times.

\section{Real-time quantitative PCR}

HMC-1 cells were seeded in a 6-wells plate and then stimulated with $50 \mathrm{nM}$ of PMA plus $1 \mu \mathrm{M}$ of A23187 and incubated at $370 \mathrm{C}$ for $8 \mathrm{~h}$. PBS were as controls. The mRNA levels of YKL-40 were determined by realtime quantitative PCR. Total RNA was extracted by Trizol reagent and the cDNA was synthesized from the total RNA by using RT reagent Kit with gDNA Eraser (Takara, Dalian, China). The following primers were used: YKL-40 (5-'AATTCGGCCTTCATTTCCTT -3', and 5'-GATAGCCTCCAACACCCAGA-3'), GAPDH (5'CGGAGTCAACGGATTTGGTC-3' and 5'-CGGTGCCATGGAATTTGCCA-3'). The mRNA levels of YKL-40 were expressed as relative mRNA levels compared with control and determined by the $2^{-\triangle \Delta C t}$ method.

\section{Measurement of vascular permeability}


As described methods(15), HDMECs were cultured on the upper chamber of transwell (Transwell membrane, $0.4 \mu \mathrm{M}$ pore size; Corning Costar). After $48 \mathrm{~h}$, the integrity and homogeneity of the endothelial monolayer were examined by microscope. The confluent monolayers were incubated with histamine (100 $\mu \mathrm{mol} / \mathrm{L}), \mathrm{YKL}-40(500 \mathrm{ng} / \mathrm{ml})$, histamine $(100 \mu \mathrm{mol} / \mathrm{L})$ plus YKL-40 (10-500 ng/ml) for $2 \mathrm{~h}$. Antihistamine (loratadine or ranitidine, $10 \mu \mathrm{mol} / \mathrm{L}$ ) were pretreated for 20 minutes. After treatment, FITC- dextran $(1 \mathrm{mg} / \mathrm{ml})$ was added into the upper chambers, and fluorescence in the lower chamber was measured one hour later with fluorescence reader.

\section{Assay for soluble VE-cadherin levels}

Levels of soluble VE-cadherin in cultured supernatants of HDMECs were detected with Human VECadherin ELISA Kit (Boster Biological Technology, Wuhan, China. Catalog \#EK1317) according to the manufacturer's instruction.

\section{Immunofluorescence}

The expression of VE-cadherin in HDMECs was detected by immunofluorescence. HDMECs, grown on glass coverslips, were treated with histamine $(100 \mu \mathrm{mol} / \mathrm{L}), \mathrm{YKL}-40(500 \mathrm{ng} / \mathrm{ml})$, histamine $(100 \mu \mathrm{mol} / \mathrm{L})$ plus YKL-40 (10-500 ng/ml) for $2 \mathrm{~h}$. Antihistamine (loratadine or ranitidine, $10 \mu \mathrm{mol} / \mathrm{L})$ were pretreated for 20 minutes. cells were fixed by $4 \%$ paraformaldehyde for $1 \mathrm{~h}$, and then incubated with VE-cadherin antibody at $4^{\circ} \mathrm{C}$ overnight (1:50 dilution; Cell Signaling Technology). 4'-6-diamidino-2-phenylindole (DAPI) was used to counterstain the nuclei for 5 minutes. Fluorescence images were captured by laser scanning confocal microscopy (Olympus, Tokyo, Japan).

\section{Western Blot Analysis}

The expression of VE-cadherin, akt and mitogen-activated protein kinases (MAPKs) in HDMECs was measured by western blot. HDMECs were treated with histamine $(100 \mu \mathrm{mol} / \mathrm{L}), \mathrm{YKL}-40(500 \mathrm{ng} / \mathrm{ml})$, histamine $(100 \mu \mathrm{mol} / \mathrm{L})$ plus YKL-40 $(10-500 \mathrm{ng} / \mathrm{ml})$ for $15 \mathrm{~min}$. Antihistamine (loratadine or ranitidine, $10 \mu \mathrm{mol} / \mathrm{L}$ ) were pretreated for 20 minutes. After treatment, total protein was extracted. Protein samples of $40 \mathrm{mg}$ were electrophoresed on $12 \%$ or $6 \%$ Tris-glycine gels, subjected to sodium dodecylsulfate polyacrylamide gel electrophoresis, and transferred to polyvinylidene fluoride membranes. Subsequently, membranes were incubated with primary antibody at $4^{\circ} \mathrm{C}$ overnight and with the appropriate HRPconjugated secondary antibody for 1 hour. The expression of VE-cadherin, akt and MAPKs (ERK, JNK and p38) was determined with enhanced chemiluminescence reagents. The results were normalized to the expression of $\beta$-actin.

\section{Statistical analysis}

The data showed in Table 1 and Figure 1 were expressed as median \pm interquartile range with MannWhitney test and Wilcoxon sign-rank test. Other datas were expressed as mean \pm SD. One-way analysis of variance was used to compare statistical differences between groups. $P<0.05$ was set as the statistically significant. 


\section{Results}

\section{Increased YKL-40 levels in HMC-1 stimulated by PMA and A23187}

To explore the origin of YKL-40 in pathogenesis of CSU, we assayed mRNA expression of YKL-40 in HMC1 stimulated by PMA and A23187. As presented in Figure 1, the mRNA levels of YKL-40 in HMC-1 stimulated by PMA and A23187 were markedly increased when compared with PBS controls $(p<0.01)$.

\section{Effect of YKL-40 on the permeability of HDMECs}

As described in the method, the amount of FITC-dextran in the lower chamber leaked from the HDMECs layer was detected to scale the permeability of HDMECs. The permeability of HDMECs with different treatments was quantified by the percentage of OD490 change. As shown in Figure 2A, YKL-40 treated alone had no effect on the permeability of HDMECs. Figure 2B showed that YKL-40 treated with histamine could significant enhanced the permeability of HDMECs when compared with histamine alone group. This study also investigated the effects of different antihistamines on the permeability of histamine-YKL-40-treated HDMECs. Our data suggested that $\mathrm{H} 1$ antihistamine (loratadine) or $\mathrm{H} 2$ antihistamine (ranitidine) cannot suppress the hyperpermeability of HDMECs induced by histamine plus YKL-40 when compared with the histamine alone group.

\section{YKL-40 induces sVE-cadherin release from HDMECs}

The previous study had indicated histamine could induce sVE-cadherin release in HMEC-1 cells and sVEcadherin levels was reached their peak value after 20 minutes to 4 hours. As presented in Figure 3, sVEcadherin levels of histamine treated alone group were significantly increased when compared with PBS control group. Moreover, sVE-cadherin levels of YKL-40 treated with histamine together group were significantly increased when compared with histamine group. This study also investigated the effects of different antihistamines on SVE-cadherin release in histamine-YKL-40-treated HDMECs. HDMECs were pretreated with different antihistamines $(10 \mu \mathrm{mol} / \mathrm{L}$ for 20 minutes $)$ and then incubated with $100 \mu \mathrm{mol} / \mathrm{L}$ of histamine and $500 \mathrm{ng} / \mathrm{ml}$ of YKL-40 for $2 \mathrm{~h}$. As shown in Figure 3, H1 antihistamine (loratadine) or H2 antihistamine (ranitidine) cannot block the release of sVE-cadherin in histamine-YKL-40-treated HDMECs when compared with the histamine alone group.

\section{YKL-40 leads to VE-Cadherin Disruption}

The disruption of VE-cadherin in HDMECs treated by histamine plus YKL-40 was observed by double staining for FITC-VE-cadherin and DAPI. As presented in Figure 4A, abundant expression of VE-cadherin was observed in control HDMECs. Obvious VE-cadherin cleavage was found in histamine-treated HDMECs. And the more disruption of VE-cadherin was observed in histamine plus YKL-40-treated cells. In contrast, $\mathrm{H} 1$ antihistamine (loratadine) and $\mathrm{H} 2$ antihistamine (ranitidine) cannot attenuated the change. 
The expression of phosphorylated VE-cadherin in HDMECs was detected by western blot. As presented in Figure 4B, histamine upregulated expression levels of phosphorylated VE-cadherin in HDMECs. The expression levels of phosphorylated VE-cadherin in histamine-YKL-40-treated HDMECs were obviously enhanced when compared the HDMECs induced by histamine alone. Meanwhile, $\mathrm{H} 1$ antihistamine (loratadine) and $\mathrm{H} 2$ antihistamine (ranitidine) cannot block the phosphorylation of VE-cadherin in histamine-YKL-40-induced HDMECs.

\section{Effects of YKL-40 on activation of Akt and p38}

To evaluate the mechanisms underlying the effects of YKL-40, we examined the potential effects of IL-35 on activation of Akt and MAPKs (ERK, JNK and p38). As shown in Figure 4C, the treatment of HDMECs with histamine plus YKL-40 resulted in an increased phosphorylation of Akt and p38 after $15 \mathrm{~min}$. $\mathrm{H} 1$ antihistamine (loratadine) and $\mathrm{H} 2$ antihistamine (ranitidine) cannot attenuate histamine plus YKL-40induced phosphorylation of Akt and p38.

\section{Discussion}

YKL-40 plays an important role in cell proliferation, microangiogenesis, acute or chronic inflammation and it is currently considered to be an important marker of endothelial dysfunction. Salomon et al had reported that YKL-40 serum level is increased in patients with atopic dermatitis and reflects the severity of symptoms(11). The enhanced levels of YKL-40 had also been found in many diseases such as asthmatic, psoriasis, secondary diabetes and peripheral artery disease. Our previous study examined the serum levels of YKL-40 in patients with CSU and healthy controls. We found that the serum YKL-40 levels were significantly increased in patients with CSU compared with healthy controls, which indicated that YKL-40 may play an important role in the pathogenesis of CSU(14).

YKL-40 can be secreted by a series of inflammatory-related cells, including tumor cells, vascular smooth muscle cells, mature neutrophils, articular synovial cells. Mast cells, as one of the major effector cells in CSU, play an integral role in the inflammatory response by accumulating at sites of inflammation and mediating the production of inflammatory cytokines(16). In this study, we found YKL-40 can be secreted by activated HMC-1 cells which stimulated by PMA and A23187.

$\mathrm{CSU}$ is a common vascular skin disease. Abundant evidence had indicated that increased vascular permeability play an important role in the occurrence and pathogenesis of CSU. Recent studies have found that YKL-40 can up-regulate the expression of vascular endothelial growth factor (VEGF) in vascular endothelial cells by inducing the coordination of membrane-bound receptor syndecan-1 and integrin av $\beta 3$, thus promoting the formation of microvessels in vascular endothelial cells(17). It is suggested that YKL-40-related receptors could be expressed in vascular endothelial cells. Muszyski et al suggested that YKL-40 can decrease the stability of blood-brain barrier and increase vascular permeability in patients with Alzheimer's disease(18). However, the effect of YKL-40 on skin vascular permeability in CSU patients is still not reported. In this study, the effect of YKL-40 on the permeability of 
HDMECs was detected. Our results suggested that YKL-40 alone cannot affect the permeability of HDMECs. However, YKL-40 could promote the permeability of HDMECs induced by histamine.

VE-cadherin is an important intercellular adhesion molecule, which plays an important role in maintaining and restoring the function of endothelial barrier. The destruction or decomposition of VE-cadherin can further lead to hemorrhage and inflammatory cell infiltration. Studies have shown that VE-cadherin can release a soluble fragment into the blood under some pathological conditions involving vascular injury. Chen et al had indicated that the serum soluble VE-cadherin in patients with CSU was significantly higher than those in patients with atopic dermatitis and healthy controls, and it is positively correlated with the disease score(19). They also found histamine could induce the release of soluble VE-cadherin in endothelial cells. However, the effect of YKL-40 synergistic with histamine to increase the permeability of HDMECs on the normal expression of VE-cadherin and the release of soluble VE-cadherin has not been reported. In this study, our data indicated that YKL-40 treated with histamine together could significantly increased the released sVE-cadherin levels when compared with histamine group. And we also found that histamine plus YKL-40 could lead to the more disruption of VE-cadherin in HDMECs observed by double staining for FITC-VE-cadherin and DAPI. The expression levels of phosphorylated VE-cadherin in histamine-YKL-40-treated HDMECs were obviously enhanced when compared the HDMECs induced by histamine alone.

Because endothelial barrier dysfunction and VE-cadherin expression are often associated with the activation of MAPKs and phosphoinositide 3-kinase (PI3-K)/AKT pathway(20; 21). To evaluate the mechanisms underlying the effects of YKL-40, we examined the potential effects of IL-35 on activation of Akt and MAPKs (ERK, JNK and p38). As shown in Fig. 5C, the treatment of HDMECs with histamine plus YKL-40 resulted in an increased phosphorylation of Akt and p38 after 15 min.

Although the second generation antihistamines are used as the first-line treatment for CSU in domestic and foreign guidelines, there are still some intractable cases that are ineffective for various antihistamines. In our study, we also study the treatment effect of $\mathrm{H} 1$ antihistamine (loratadine) and $\mathrm{H} 2$ antihistamine (ranitidine) on the HDMECs treated with histamine plus YKL-40. However, $\mathrm{H} 1$ antihistamine (loratadine) and $\mathrm{H} 2$ antihistamine (ranitidine) cannot attenuate the effect including the permeability changes and the expression of VE-cadherin. It is suggested that YKL-40 may be an inflammatory molecule that is not inhibited by antihistamines, which mediates the increase of vascular permeability and thus induces the occurrence and development of CSU.

Taken together, this study provides first observations on the association of YKL-40 and CSU, and showed the increased YKL-40 serum levels in CSU patients. In vitro, YKL-40 significantly promoted the permeability changes and leaded to the released, disruption of VE-cadherin in HDMECs induced by histamine. Furthermore, YKL-40 also enhanced the Ark and p38 pathways. Therefore, we suggest that YKL-40 may serve as pro-permeability cytokines, and play a role in the pathogenesis of CSU. This study will help to further elucidate the pathogenesis of CSU and provide a new target for the development of anti-histamine resistance drugs for CSU. 


\section{Declarations}

Ethics approval and consent to participate: Not applicable

Consent for publication: Not applicable

Availability of data and materials: All data generated or analysed during this study are included in this published article

Competing interests: The authors declare no conflict of interest.

Funding: The study was supported by Health and Family Planning Commission of Sichuan Provincial (130409).

Authors' contributions:

concept, design, definition of intellectual content: Peimei Zhou and Lin Wang

literature search: Lixin Fu and Tao Chen

experiment studies: Peimei Zhou and Lixin Fu

data acquisition and data analysis: Wenju Wang, Shihua Zeng Lin Li and Li Han

manuscript preparation: Peimei Zhou, Lixin Fu and Tao Chen

manuscript editing: Tao Chen and Yonghong Lu

manuscript review: Lin Wang

Acknowledgements: Not applicable

Conflict of interest statement

The authors declare no conflict of interest.

Clinical Trial Registration:

Trial registration: Not applicable

\section{References}

1. Zuberbier T, Aberer W, Asero R, Bindslev-Jensen C, Brzoza Z, et al. 2014. The EAACl/GA(2) LEN/EDF/WAO Guideline for the definition, classification, diagnosis, and management of urticaria: the 2013 revision and update. Allergy 69:868-87 
2. Bossi F, Frossi B, Radillo O, Cugno M, Tedeschi A, et al. 2011. Mast cells are critically involved in serum-mediated vascular leakage in chronic urticaria beyond high-affinity lgE receptor stimulation. Allergy 66:1538-45

3. Vestweber D. 2008. VE-cadherin: the major endothelial adhesion molecule controlling cellular junctions and blood vessel formation. Arterioscler Thromb Vasc Biol 28:223-32

4. Kumar P, Shen Q, Pivetti CD, Lee ES, Wu MH, Yuan SY. 2009. Molecular mechanisms of endothelial hyperpermeability: implications in inflammation. Expert Rev Mol Med 11:e19

5. Libreros S, Iragavarapu-Charyulu V. 2015. YKL-40/CHI3L1 drives inflammation on the road of tumor progression. J Leukoc Bio/98:931-6

6. Chimenti MS, Triggianese P, Conigliaro P, Candi E, Melino G, Perricone R. 2015. The interplay between inflammation and metabolism in rheumatoid arthritis. Cell Death Dis 6:e1887

7. Kastrup J. 2012. Can YKL-40 be a new inflammatory biomarker in cardiovascular disease? Immunobiology 217:483-91

8. Dela Cruz CS, Liu W, He CH, Jacoby A, Gornitzky A, et al. 2012. Chitinase 3-like-1 promotes Streptococcus pneumoniae killing and augments host tolerance to lung antibacterial responses. Cell Host Microbe 12:34-46

9. Kumagai E, Mano Y, Yoshio S, Shoji H, Sugiyama M, et al. 2016. Serum YKL-40 as a marker of liver fibrosis in patients with non-alcoholic fatty liver disease. Sci Rep 6:35282

10. Hansen M, Nielsen AR, Vilsboll T, Lund A, Krarup T, et al. 2012. Increased levels of YKL-40 and interleukin 6 in patients with chronic pancreatitis and secondary diabetes. Pancreas 41:1316-8

11. Salomon J, Matusiak L, Nowicka-Suszko D, Szepietowski JC. 2017. Chitinase-3-Like Protein 1 (YKL40) Reflects the Severity of Symptoms in Atopic Dermatitis. J Immunol Res 2017:5746031

12. Tang H, Fang Z, Sun Y, Li B, Shi Z, et al. 2010. YKL-40 in asthmatic patients, and its correlations with exacerbation, eosinophils and immunoglobulin E. Eur Respir J 35:757-60

13. Erfan G, Guzel S, Alpsoy S, Rifaioglu EN, Kaya S, et al. 2015. Serum YKL-40: a potential biomarker for psoriasis or endothelial dysfunction in psoriasis? Mol Cell Biochem 400:207-12

14. Zhou PM, Fu LX, Chen T, Wang L, Lu YH. 2019. Elevated YKL-40 serum levels in patients with chronic spontaneous urticaria. Ann Allergy Asthma Immunol 123:404-5

15. Orlova VV, Economopoulou M, Lupu F, Santoso S, Chavakis T. 2006. Junctional adhesion molecule-C regulates vascular endothelial permeability by modulating VE-cadherin-mediated cell-cell contacts. $J$ Exp Med 203:2703-14

16. Shakoory B, Fitzgerald SM, Lee SA, Chi DS, Krishnaswamy G. 2004. The role of human mast cellderived cytokines in eosinophil biology. J Interferon Cytokine Res 24:271-81

17. Shao R, Hamel K, Petersen L, Cao QJ, Arenas RB, et al. 2009. YKL-40, a secreted glycoprotein, promotes tumor angiogenesis. Oncogene 28:4456-68

18. Muszynski P, Kulczynska-Przybik A, Borawska R, Litman-Zawadzka A, Slowik A, et al. 2017. The Relationship between Markers of Inflammation and Degeneration in the Central Nervous System and 
the Blood-Brain Barrier Impairment in Alzheimer's Disease. J Alzheimers Dis 59:903-12

19. Chen T, Guo ZP, Wang WJ, Fu LX, Sun QM, Zhou PM. 2017. Increased serum soluble vascular endothelial cadherin levels in patients with chronic spontaneous urticaria. Ann Allergy Asthma Immuno/ 118:704-9

20. Khanna P, Yunkunis T, Muddana HS, Peng HH, August A, Dong C. 2010. p38 MAP kinase is necessary for melanoma-mediated regulation of VE-cadherin disassembly. Am J Physiol Cell Physiol 298:C1140-50

21. Dossumbekova A, Berdyshev EV, Gorshkova I, Shao Z, Li C, et al. 2008. Akt activates NOS3 and separately restores barrier integrity in $\mathrm{H} 2 \mathrm{O} 2$-stressed human cardiac microvascular endothelium. Am J Physiol Heart Circ Physiol 295:H2417-26

\section{Tables}

Table 1 is not available with this version

\section{Figures}

\section{YKL40}

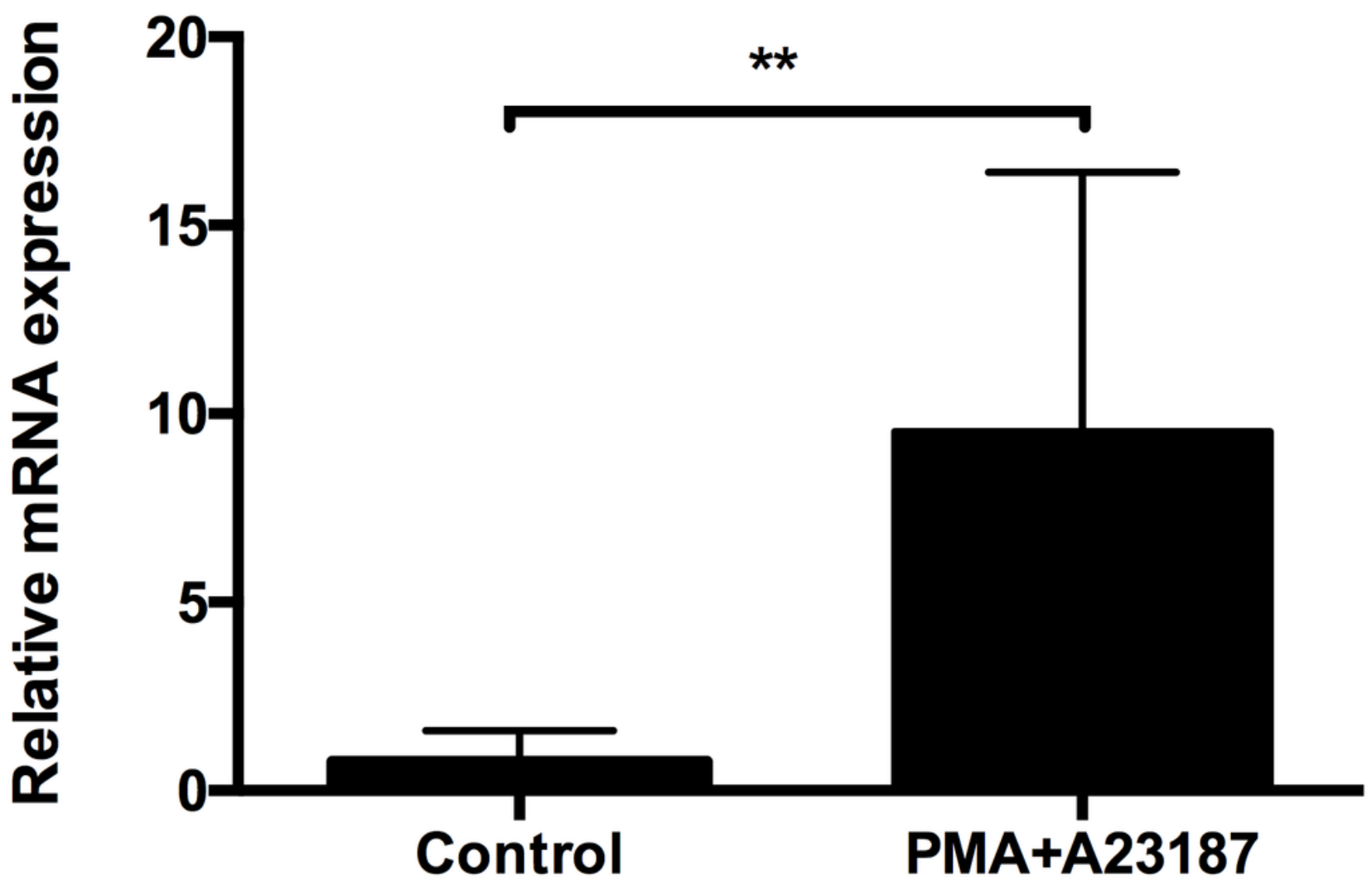


Figure 1

Enhanced mRNA expression of YKL-40 in HMC-1 cells stimulated by PMA and A23187. HMC-1 cells were stimulated with PMA (50 nM) plus A23187 $(1 \mu \mathrm{M})$ for $8 \mathrm{~h}$. After that, mRNA expression of YKL-40 in HMC1 cells were measured by Real-time quantitativePCR. The mRNA expression of YKL-40 in simulated HMC1 were significantly increased when compared with control cells. All data are expressed as Mean \pm SD. P values are based on the $t$ test. $n=10 .{ }^{*} \mathrm{P}<0.01$.
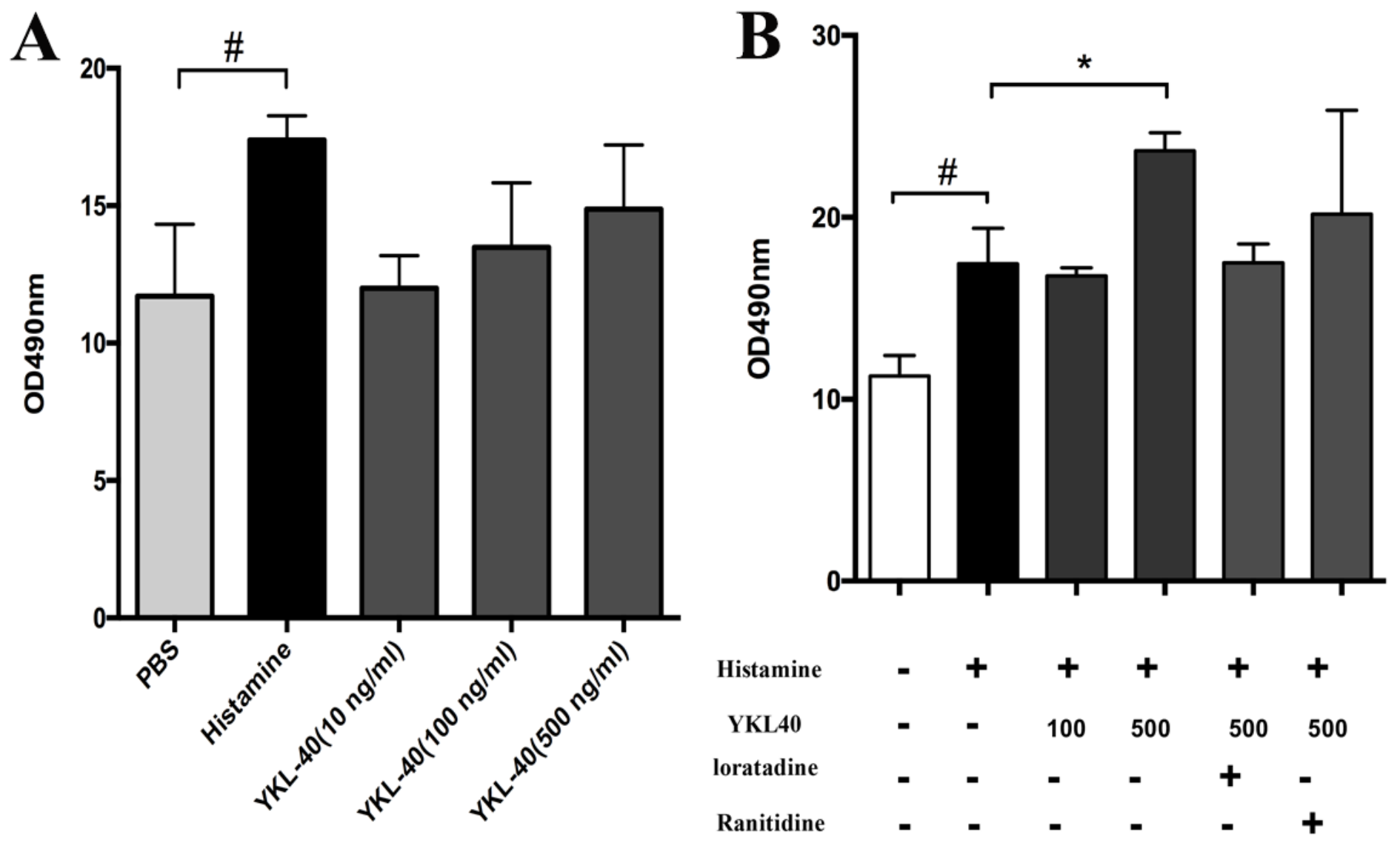

Figure 2

YKL-40 enhanced the permeability of HDMECs induced by histamine. As described in the Methods, the OD490 in the lower chamber were calculated for displaying the permeability of HDMECs. A: Effect of YKL40 at different concentrations on the permeability of HDMECs. B: Effect of YKL-40 and Histamine on the permeability of HDMECs. \#P<0.05 compared to the control group. ${ }^{*}<<0.05$ compared to the group only treated with histamine. 


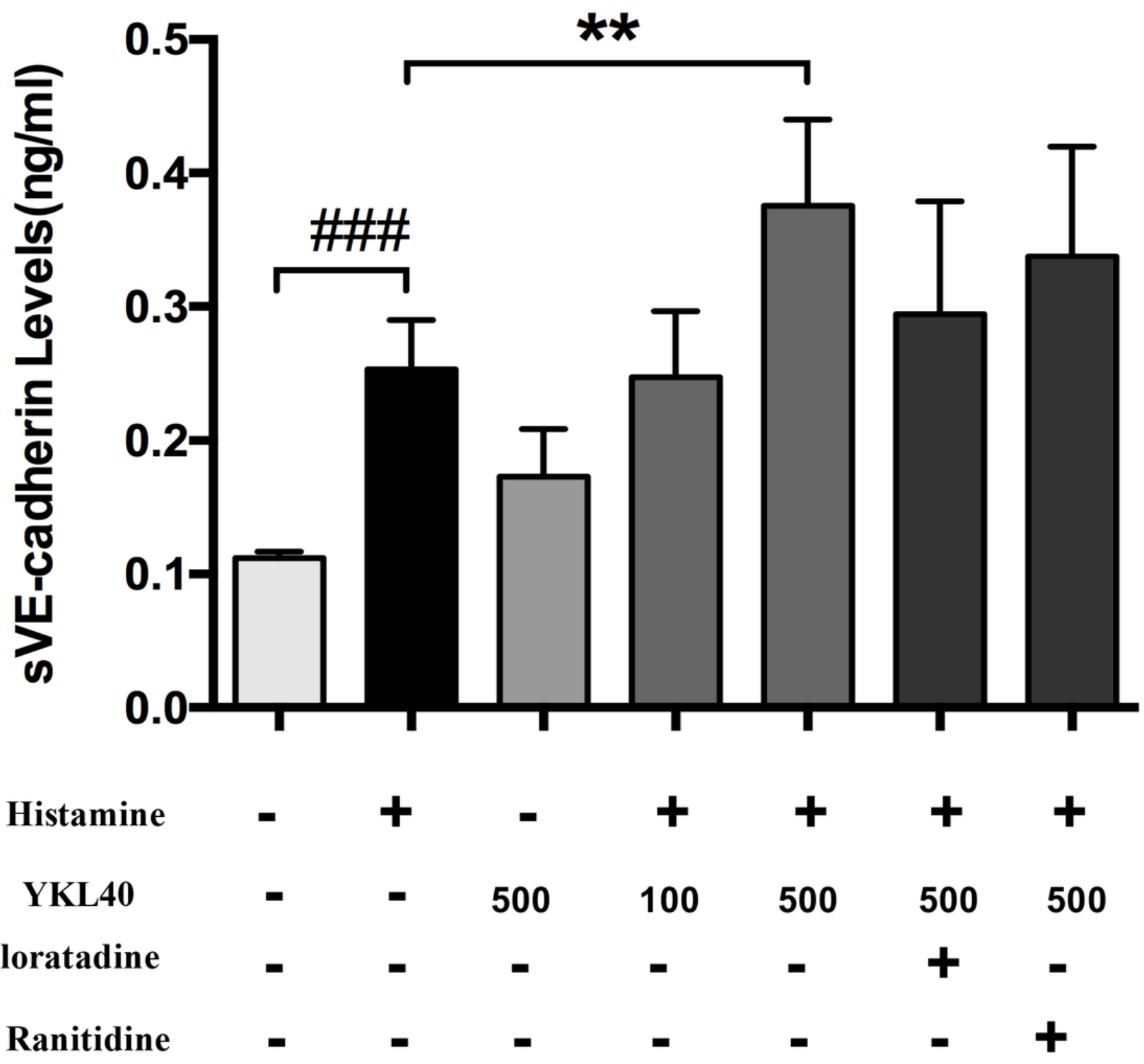

Figure 3

YKL-40 increased the sVE-cadherin release from HDMECs cells induced by histamine. HDMECs were treated with histamine $(100 \mu \mathrm{mol} / \mathrm{L}), \mathrm{YKL}-40(500 \mathrm{ng} / \mathrm{ml})$, histamine $(100 \mu \mathrm{mol} / \mathrm{L})$ plus YKL-40 (10-500 $\mathrm{ng} / \mathrm{ml}$ ) for $15 \mathrm{~min}$. Antihistamine (loratadine or ranitidine, $10 \mu \mathrm{mol} / \mathrm{L}$ ) were pretreated for 20 minutes. $\mathrm{H} 1$ antihistamine (loratadine) or $\mathrm{H} 2$ antihistamine (ranitidine) cannot block the release of sVE-cadherin in histamine-YKL-40-treated HDMECs when compared with the histamine alone group. Values were expressed as mean \pm SD. One-way analysis of variance was used to compare statistical differences between groups. \#\#\#P<0.0001 compared to the control group. ${ }^{*} \mathrm{P}<0.01$ compared to the group only treated with histamine. 

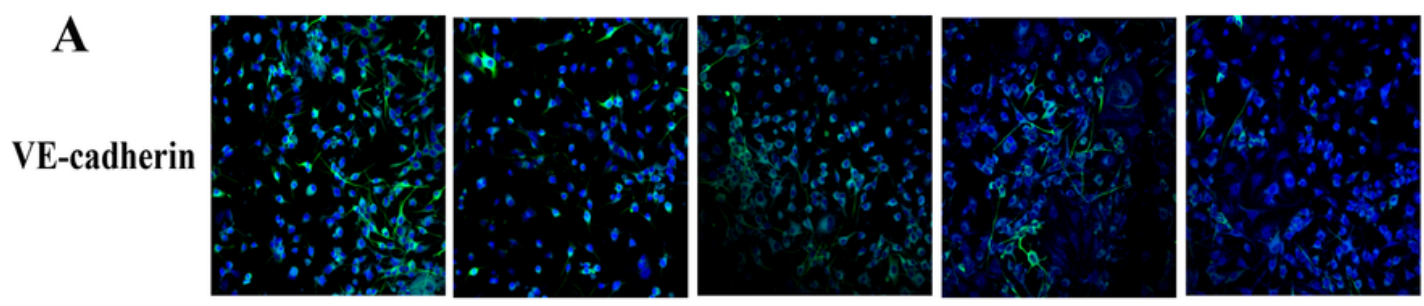

Histamine

YKL40

loratadine

Ranitidine

\section{B}

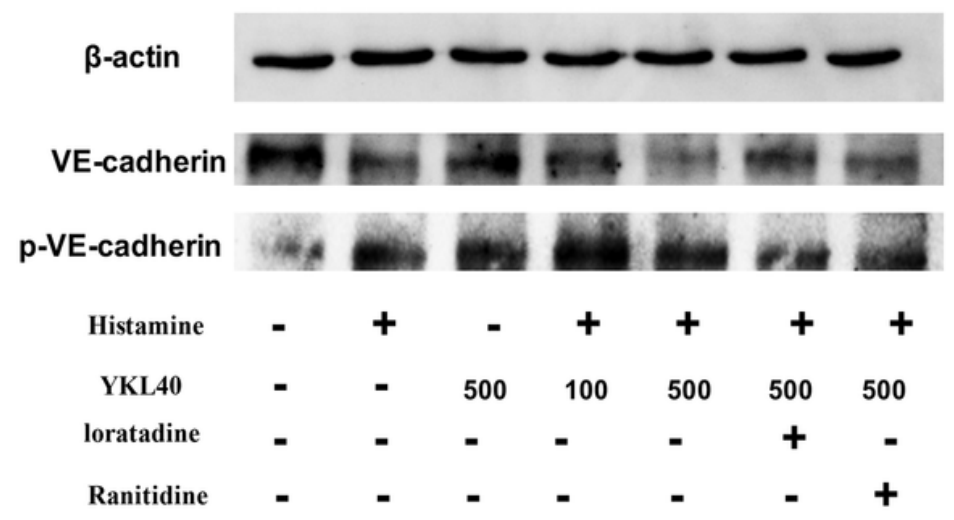

C

Akt

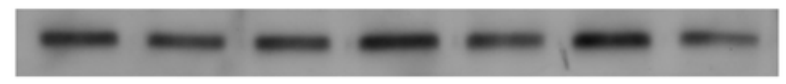

p-Akt

P38

p-P38

Histamine

YKL40

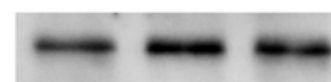

loratadine

Ranitidine
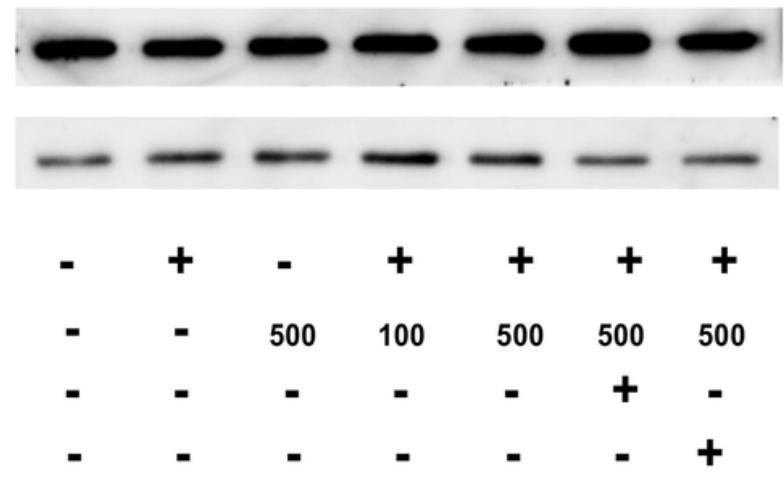
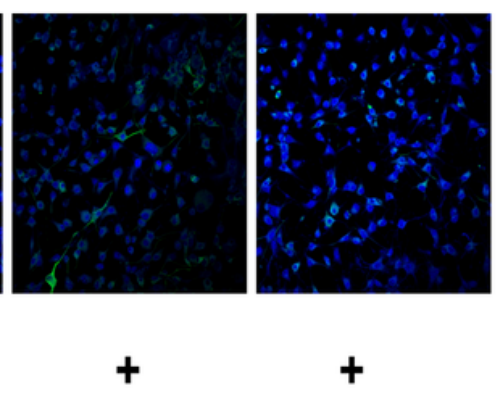

500

$+$

\section{$+$ \\ 500}

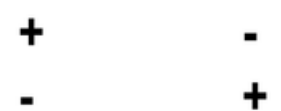

\section{Figure 4}

YKL-40 promoted the VE-cadherin phosphorylation and VE-cadherin disruption and increased phosphorylation of Akt and p38 in HDMECs induced by histamine. HDMECs were treated with histamine $(100 \mu \mathrm{mol} / \mathrm{L})$, YKL-40 $(500 \mathrm{ng} / \mathrm{ml})$, histamine $(100 \mu \mathrm{mol} / \mathrm{L})$ plus YKL-40 (10-500 ng/ml) for $15 \mathrm{~min}$.

Antihistamine (loratadine or ranitidine, $10 \mu \mathrm{mol} / \mathrm{L}$ ) were pretreated for 20 minutes. (A) After treatment, the expression of VE-cadherin in HDMECs was observed by immunofluorescence double staining for FITC-VEcadherin and DAPI. (B) Afterward, protein samples were obtained to measure expression levels of phosphorylated VE-cadherin by western blots. (C) Phosphorylation of Akt and p38 MAPKs was analyzed by western blotting.

Image not available with this version 
Figure 5

Figure not available in this version 